\title{
JOGO DE PAPÉIS OU JOGO PROTAGONIZADO NA ORGANIZAÇÃO DO ENSINO NA EDUCAÇÃO INFANTIL
}

\author{
JUEGO DE PAPELES O JUEGO PROTAGONIZADO EN LA ORGANIZACIÓN \\ DE LA ENSEÑANZA EN LA EDUCACIÓN INFANTIL
}

\section{GAME OF PAPERS OR PROTAGONIZED GAME IN THE ORGANIZATION OF EDUCATION IN CHILDREN EDUCATION}

\author{
Rita de CÁSSIA DUARTE ${ }^{1}$ \\ José Luis DERISSO ${ }^{2}$ \\ Elaine Cristina MELO DUARTE ${ }^{3}$ \\ Newton DUARTE ${ }^{4}$
}

Resumo: Os temas abordados neste artigo estão centrados nos estudos da periodização do desenvolvimento psíquico elaborada por Danill Elkonin a partir dos fundamentos teórico-metodológicos da psicologia histórico-cultural propostos por Vigotski e Leontiev. É analisado o desenvolvimento mental como parte do desenvolvimento da personalidade no contexto da educação infantil na perspectiva da pedagogia históricocrítica de Dermeval Saviani.

PALAVRAS-CHAVE: Educação infantil. Psicologia histórico-cultural. Pedagogia histórico-crítica.

RESUMEN: Los temas abordados en este artículo se centra en los estudios de la periodización del desarrollo psíquico elaborada por Danill Elkonin a partir de los fundamentos teórico-metodológicos de la psicología histórico-cultural propuestos por Vigotski y Leontiev. Se analiza el desarrollo mental como parte del desarrollo de la personalidad en el contexto de la educación infantil en la perspectiva de la pedagogía histórico-crítica de Dermeval Saviani.

PALABRAS CLAVE: Educación infantil. Psicología histórico-cultural. Pedagogía histórico-crítica.

${ }^{1}$ Doutoranda do Programa de Pós-Graduação em Educação Escolar na UNESP Araraquara e Membro do grupo de pesquisa "Estudos Marxistas em Educação", da Universidade Estadual Paulista Júlio de Mesquita Filho. E-mail: ritaduartederisso@yahoo.com.br

2 Professor Adjunto de Fundamentos da Educação na UNIOESTE - Cascavel/PR; Doutor em Educação Escolar; Membro do grupo de pesquisa "Estudos Marxistas em Educação" da UNESP/ Araraquara e do Grupo de Estudos e Pesquisas em "História, Sociedade e Educação no Brasil" - GT da Região Oeste do Paraná - "HISTEDOPR"; E-mail: joseluisderisso@yahoo.com.br

3 Mestranda do Programa de Pós-Graduação em Educação na Universidade Estadual de Campinas, UNICAMP. Membro do grupo de pesquisa: História, Sociedade e Educação no Brasil”, HISTEDBR, GT Unicamp. E-mail: elainecmduarte@outlook.com.br

${ }^{4}$ Professor Titular do Departamento de Psicologia da Educação, da Faculdade de Ciências e Letras, Unesp/Araraquara E-mail: newton.duarte@uol.com.br 
ABSTRACT: This paper approaches issues about stages of mental development based on the work of Daniil El'konin and the theoretical methodological foundations of historical cultural psychology in L. S. Vygotsky and A. N. Leont'ev. It is analyzed the mental development as part of the development of personality in the context of childhood school education from the perspective of historical critical pedagogy of Dermeval Saviani.

KEYWORDS: Childhood education. cultural historical psychology. historical critica pedagogy.

\title{
Introdução
}

\begin{abstract}
A brincadeira de papéis influencia decisivamente o desenvolvimento global da criança. Ao brincar, ela aprende a ser e agir diante das coisas e das pessoas, pois, é a partir das ações práticas realizadas que os processos internos se estruturam, orientando outras ações práticas, mais autônomas e complexas, que enriquecerão os passos internos e assim sucessivamente. Portanto, as brincadeiras infantis destacam-se no vasto campo social que circunscreve a vida da criança e que representa a base do desenvolvimento de todos os atributos e propriedade humana (Martins, 2006, p. 42).
\end{abstract}

A ênfase que damos à Educação Infantil, primeira etapa da educação básica obrigatória, está pautada na contribuição de Elkonin (2009), partindo do pressuposto de que a mesma apresenta suporte teórico-metodológico no âmbito da pedagogia que leva em conta as necessidades das crianças nesta fase da vida, oferecendo atividades lúdicas por meio do jogo de papéis, ou jogo protagonizado, permitindo ao professor romper com princípios acríticos que valorizam atividades educativas reprodutivas desprovidas de objetos culturais relevantes e ensejando resultados positivos no que diz respeito à aquisição pela criança de conhecimentos que elevem seu universo cultural, aprimorem sua sensibilidade social, instrumentalizando o desenvolvimento de sua capacidade crítica.

\section{Contribuição da psicologia histórico-cultural e da periodização do desenvolvimento psíquico para se pensar na educação escolar}

A psicologia histórico-cultural é também conhecida como Escola de Vigotski, em alusão ao seu principal formulador. Foi gestada a partir dos desafios que se colocaram no campo da educação a partir do processo da Revolução Russa iniciada em 1917, sob a liderança, conforme já dissemos, de Lev Semenovitch Vigotski e com a 
participação de pesquisadores tais como Alexei N. Leontiev, Daniil B. Elkonin, Alexander R. Luria e Vasili V. Davidov, entre outros.

A psicologia histórico-cultural procurou, desde seu início, situar-se no interior do marxismo e desenvolver uma teoria psicológica cuja base filosófica fosse o materialismo histórico e filosófico. Como explica Martins (2011, p. 2),

\begin{abstract}
A dedicação de Vigotski e de demais psicólogos a ele vinculados, a exemplo de Leontiev e Luria, aos estudos dos aspectos que realmente diferenciam os psiquismos humano e dos demais animais colocou no cerne da questão o desenvolvimento de propriedades cuja formação subjuga-se à apropriação da cultura. Consideramos também que, não por acaso, Vigotski, juntamente com Leontiev e Luria, defenderam que o estudo do desenvolvimento social do psiquismo humano fosse o verdadeiro objeto da psicologia científica.
\end{abstract}

Vigotski se fundamenta na tese segundo a qual o desenvolvimento do psiquismo humano é, sobretudo, de natureza histórico-social. Em outras palavras, o ser humano é um sujeito que se forma em função das condições de vida, de educação e cultura que lhe são oferecidas.

Da parceria entre os soviéticos surge a psicologia histórico-cultural da periodização do desenvolvimento, segundo escreve Pasqualini (2016, p.63) "um importante capítulo do projeto coletivo de construção de uma nova psicologia verdadeiramente científica - apoiada em bases materialistas dialéticas”. Possibilitando “uma nova forma de pensar o desenvolvimento humano" Pasqualini (2016.p 64).

Importante destacar que a teoria histórico-cultural da periodização do desenvolvimento humano traz por base filosófica a compreensão das categorias e princípios do Método materialista histórico-dialético desenvolvido por Marx e Engels que superaram por incorporação o método dialético idealista de Hegel. O método de Marx e Engels sustenta a tese da centralidade da atividade do trabalho no processo de formação do ser humano enquanto ser social, que induz à constatação de que a sociedade é um produto histórico e - a partir das contradições de classe surgidas no processo de desenvolvimento histórico - que o motor da história tem sido, desde o final da chamada pré-história, a luta de classes. O reconhecimento de que a luta de classes é um fenômeno historicamente superável requer que os seres humanos se posicionem em termos da superação ou da naturalização desse fenômeno. No atual estágio histórico, em que o capitalismo tende a acirrar a contradição entre a necessidade de desenvolvimento das forças produtivas e os obstáculos criados a esse desenvolvimento pelas relações de produção capitalistas, a superação dessa forma de organização social torna-se uma 
questão de sobrevivência da própria espécie humana e de outras formas de vida em nosso planeta. Apontar para esse dramático quadro histórico do gênero humano é necessário para se concretizar a premissa vigotskiana de que o psiquismo humano é essencialmente social e cultural, evitando-se assim que sociedade e cultura sejam tratadas de forma abstrata e idealista.

$\mathrm{Na}$ perspectiva dialética que fundamenta os estudos sobre a periodização do desenvolvimento, Vigotski argumenta que em função das circunstâncias históricosociais nas quais os indivíduos estão inseridos, torna-se praticamente impossível de se estabelecer um modelo Linear, naturalizado e universal de desenvolvimento psíquico. $\mathrm{Na}$ infância tal desenvolvimento será desencadeado a partir da mediação dos outros seres humanos, especialmente os adultos, destacando-se que esse desenvolvimento terá mais chances de alcançar os níveis mais elevados se essa mediação for intencionalmente direcionada pelo comprometimento do adulto com o processo formativo da criança. $\mathrm{O}$ que pressupõe que em situações adequadas e com intervenções pontuais a criança será capaz de interiorizar as melhores qualidades humanas. Entendendo-se aqui como qualidades humanas aquelas produzidas no curso da história, no processo de construção de um mundo da cultura, essas "qualidades humanas" formam-se ao longo da história social por meio da incorporação das potencialidades biológicas da espécie humana à dinâmica sociocultural caracterizada pelas relações dialéticas entre teleologia e causalidade (Lukács, 2013) e entre objetivação e apropriação (Duarte, 2013).

Leontiev, Elkonin e Davídov empenharam-se no estudo da periodização do desenvolvimento psíquico propondo que a cada estágio existiria uma atividade que seria a principal impulsionadora do desenvolvimento, razão pela qual ela pode ser chamada de atividade dominante ${ }^{5}$. Como explica Pasqualini (2016, p. 72):

a mudança de atividade representa um salto qualitativo que se produz com o acúmulo gradual de formação, aprimoramento e requalificação de ações e operações. Como implicação pedagógica, fica evidente que o investimento na formação de novas ações e automatização de operações no interior de um dado período do desenvolvimento mostrase, assim, fundamental, como condição para a gênese e o desenvolvimento da nova atividade dominante.

Nessa perspectiva ganha relevância a educação escolar, desde que se entenda a educação escolar na sociedade burguesa como um espaço marcado pela luta de classes e por contradições. Como explica Saviani (2005), embora a escola existisse em

${ }^{5}$ A depender da tradução das obras de Vigotski e de seus colaboradores encontramos as expressões "atividade dominante", "atividade principal" ou "atividade guia" para designar o mesmo fenômeno. 
sociedades pré-capitalistas, não desempenhava nelas o papel de forma dominante de educação, o que só passou a ocorrer na sociedade burguesa em razão tanto do fato de que certos conhecimentos básicos se tornaram necessários à formação de certos extratos da classe trabalhadora, como também do fato de que era preciso difundir uma sociabilidade adequada às relações capitalistas de produção. Surgiu assim uma contradição entre a socialização do conhecimento pela escola e os limites impostos a essa socialização pelos horizontes bastante estreitos que a sociedade burguesa coloca para a vida dos indivíduos da classe trabalhadora. Essa contradição foi se tornando mais aguda pelo fato de que a ampliação dos sistemas escolares públicos ocorreu no momento histórico em que a burguesia já era classe consolidada no poder, portanto, classe reacionária, cujos interesses estavam cada vez mais em colisão com a produção e difusão de conhecimento objetivo sobre a realidade social.

Entendendo-se o caráter contraditório da escola pública, abre-se a possibilidade de afirmá-la a partir da perspectiva de socialização do conhecimento, contra a orientação burguesa que pretende limitar a educação escolar da classe trabalhadora aos processos de adaptação aos ditames dos processos de reprodução do capital.

É nessa perspectiva politicamente engajada de afirmação da escola como instituição de socialização do conhecimento em suas formas mais ricas, que Saviani (2005, p.13) assevera que:

O objeto da educação diz respeito, de um lado, à identificação dos elementos culturais que precisam ser assimilados pelos indivíduos da espécie humana para que eles se tornem humanos e, de outro lado e concomitantemente, à descoberta das formas mais adequadas para se atingir esse objetivo. Quanto ao primeiro aspecto (a identificação dos elementos culturais que precisam ser assimilados) trata-se de distinguir entre o essencial e o acidental, o principal e o secundário, o fundamental e o acessório. Aqui me parece de grande importância, em pedagogia, a noção de "clássico". O clássico não se confunde com o tradicional e também não se opõe, necessariamente, ao moderno e muito menos ao atual. O clássico é aquilo que se firmou como fundamental, como essencial.

Dessa passagem podemos apreender que a educação escolar, independente da modalidade de ensino, tem um papel social a cumprir que do nosso ponto de vista é o da transmissão dos conteúdos clássicos, sistematizados e imprescindíveis à formação humana. O que não significa, como erroneamente entendem alguns críticos da pedagogia histórico-crítica, que essa transmissão venha a ocorrer de maneira arbitrária e autoritária, ignorando-se as características essencialmente socioculturais do psiquismo de cada aluno. Nesse aspecto tem especial importância a compreensão das 
características das atividades dominantes que componham os estágios de desenvolvimento pelos quais passe a criança na idade de zero a cinco anos que, no atual sistema educacional brasileiro, corresponde ao nível da educação infantil.

\section{A função social da educação infantil}

Nesta seção faremos breve exposição dos caminhos percorridos pela educação infantil no Brasil para refletirmos sobre processos educativos intencionais tendo por base filosófica a contribuição da pedagogia histórica-critica. Antes, porém, registramos nossa adesão à concepção de escola expressa na passagem que segue:

Advogamos o princípio segundo o qual a escola, independentemente da faixa etária que atenda, cumpra a função de transmitir conhecimentos, isto é, de ensinar como lócus privilegiado de socialização para além das esferas cotidianas e dos limites inerentes à cultura do senso comum. Martins (2009, p.94).

No século XIX começou a surgir, no Brasil, a ideia de se atender crianças antes da idade então estabelecida como referência para o início da escolarização (DEL PRIORI, 2004; CAMPOS, ROSEMBERG, FERREIRA, 1993). Inspiradas no modelo europeu, surgem escolas ligadas às instituições assistenciais. A partir do século XX, com o processo de expansão industrial e urbano, as mulheres começam a exercer atividades fora do âmbito familiar impondo, assim, a necessidade de criação de creches para abrigar os filhos das mulheres trabalhadoras, uma vez que se torna necessário viabilizar a expansão do trabalho feminino remunerado, necessidade ditada pela dinâmica da produção fabril naquele contexto.

Importante notar que as creches não se associam inicialmente à ideia de educação escolar, limitando-se à finalidade de cuidar das crianças. Com o aumento da demanda por este serviço inicia-se uma discussão voltada para a especificidade das creches e da educação infantil enquanto espaços de amparo, desenvolvimento e aprendizagem da criança, bem como, da necessidade do Estado assumir essa modalidade de educação.

No âmbito legal, é a partir da Constituição de 1988 que a educação infantil é assumida definitivamente como de responsabilidade do Estado, cabendo ao mesmo mantê-la de forma plena, promovendo aprendizagem, integração e socialização das crianças pequenas. 
Após a aprovação da Lei de Diretrizes e Bases da Educação Nacional, Lei $\mathrm{n}^{\circ}$ 9394/966 , relativamente à educação infantil, merece destaque a Lei 12.796/2013 que determina a obrigatoriedade do acesso da criança na modalidade de ensino da educação infantil, a partir dos quatro anos de idade, cuja finalidade é a de "promover um desenvolvimento integral da mesma abrangendo aspectos físico, psicológico, intelectual e social, complementando a ação da família e da comunidade” (BRASIL, 2013).

Vencida a etapa legal, surgem necessidades pedagógicas referentes à organização de um ensino que promova processos significativos de aprendizagem e de desenvolvimento para a criança que se encontra na faixa etária da educação infantil, superando concepções que limitam a educação infantil a um espaço para brincadeiras espontâneas monitoradas por professores cuja função principal estaria reduzida à garantia de bem-estar físico das crianças.

Considerando-se que a criança não nasce humanizada e que a educação, desde o primeiro ano de vida, é um processo de formação, no indivíduo, das características definidoras do gênero humano, a educação infantil precisa ser a efetivação de projetos intencionalmente voltados para essa produção do humano na criança. Cabe à escola e aos professores a tarefa de ensinar às crianças aquilo que é necessário à produção do seu desenvolvimento, organizando todos os meios requeridos para que a aprendizagem ocorra da melhor forma possível.

Sendo assim, pensar em uma organização de ensino voltado para o desenvolvimento infantil pressupõe compreendermos que o trabalho pedagógico deve ser pensado e planejado entre os pares e que as ações estabelecidas em conjunto devam superar o nível da espontaneidade e do senso comum muitas vezes alienante.

Segundo nos alerta Lazaretti (2016, p. 145):

[...] compreender esse período do desenvolvimento e suas características é importante e essencial, porém não é suficiente para se organizar o ensino. Esse conhecimento responde a uma das faces desse processo, ou seja, quem é o sujeito a quem se destina o ensino? A partir dessa pergunta, é preciso refletir sobre outras questões fundamentais: Quais conteúdos são essenciais para que o ensino possa potencializar esse desenvolvimento? Quais objetivos são representativos para essa tarefa? Quais recursos e estratégias são mais adequados? Para responder a essas questões, uma palavra sintetiza: critério.

${ }^{6}$ Para uma leitura critica sobre a elaboração da LDB indicamos a leitura de SAVIANI, Dermeval. A nova lei da educação: trajetória, limites e perspectivas. Campinas: Autores Associados, 1997. 
A compreensão que se tem é que não basta apenas boa vontade da parte do professor, mas faz-se necessária a utilização de critérios consistentes na seleção dos conteúdos e das atividades lúdicas, há de se pensar no momento dessa triagem se os mesmos são relevantes, se são adequados à faixa etária, se valorizam a socialização, se agregam valores culturais que permitam apropriação de conhecimentos e promoção do desenvolvimento da criança, ou seja, se são essenciais ou secundários para compor o currículo da educação infantil.

A educação infantil, portanto, requer o mesmo nível de intencionalidade que todos os demais níveis de educação escolar. Trata-se daquilo que a pedagogia históricocrítica (SAVIANI, 2005) postula como essência do trabalho educativo, ou seja, a produção direta e intencional da humanidade nos indivíduos.

Tal intencionalidade se faz necessária tendo em vista que vivemos um período em que é supervalorizada a prática e, no caso da educação, considera-se natural que seja uma prática eclética e baseada no conhecimento tácito, tornando-se a teorização inútil ou, pior ainda, um vício a ser superado. $\mathrm{O}$ cultivo da banalidade própria às formas mais alienadas de vida cotidiana passa a ser visto como superação de intelectualismos elitistas.

Duarte (2006, p. 95) levanta esse alerta ao tratar da importância da intervenção direcionada do professor nas atividades educativas desta modalidade de ensino:

[...] a brincadeira de papéis sociais não se desenvolve espontaneamente, ela requer ações educativas que promovam $o$ surgimento, o desenvolvimento e o direcionamento desse tipo de atividade. (..) se for deixada ao sabor da espontaneidade infantil, o mais provável será que essa atividade reproduzirá espontaneamente a alienação próprias aos papéis sociais com uma presença mais marcante no cotidiano da sociedade contemporânea. Isso é absolutamente óbvio, mas só o é para quem admita a existência desse cotidiano alienado, o que não acontece com boa parte dos educadores e dos pesquisadores em educação nos dias de hoje, os quais tendem a ignorar o fenômeno social da alienação e acabam por adotar uma visão que naturaliza o cotidiano, seja na versão idealizada do cotidiano extraescolar como sinônimo da autenticidade da infância, seja na versão patologizante do cotidiano extraescolar, especialmente o familiar, como gerador dos "problemas de aprendizagem" e "problemas de comportamento" que dificultariam ou até mesmo impediriam a realização do trabalho educativo na escola.

Desta forma, o trabalho docente em todas as modalidades de ensino deve superar o nível de ações alienantes e de senso comum, resgatando assim a função social e nuclear da escola que, de acordo com Saviani (2005, p. 16), é a "transmissão- 
assimilação de conhecimentos sistematizados pela humanidade". Importante nesse momento esclarecer, utilizando-se das palavras de Duarte (2016), que para a pedagogia histórico-crítica - orientação pedagógica que ressalta a importância da educação escolar primar pela valorização dos saberes elaborados nos âmbito das ciências, da filosofia e das artes - não existe um modelo ou mesmo uma técnica específica para se ensinar:

[...] posto que a decisão pelo emprego de uma estratégia, uma técnica ou um procedimento didático dependerá sempre de uma avaliação que relacione, no mínimo, quatro elementos: quem está ensinando, quem está aprendendo, o que está sendo ensinado e em que circunstâncias a atividade educativa se realiza. Duarte (2016, p. 109).

Relativamente à educação infantil, segmento obrigatório do ensino fundamental que envolve crianças de 3 a 6 anos de idade, temos clareza dos limites que se impõem à aprendizagem, sobretudo se levamos em conta os diferentes níveis de abstração de cada faixa etária, e entendemos que cabe ao professor selecionar de forma criteriosa os objetos culturais (conteúdos escolares) e proporcionar situações de ensino e aprendizagem condizentes com as necessidades e possibilidades de cada faixa etária. Neste sentido, por meio do jogo de papéis ou jogo protagonizado fundamentado na obra de Daniil Elkonin é possível pensar na organização do ensino na educação infantil, conforme veremos na sequência.

\section{Jogo de papéis ou jogo protagonizado na educação infantil}

Neste tópico trazemos à tona a contribuição de Elkonin em sua obra Psicologia do Jogo, que apresenta subsídios teóricos, metodológicos e pedagógicos para a educação infantil. Esta obra versa sobre a importância de atividades lúdicas por meio do jogo de papéis ou jogo protagonizado.

Elkonin (2009), com base nos princípios da teoria histórico-cultural da periodização do desenvolvimento psíquico, dedicou-se a estudar, a partir do conceito de atividade-guia formulado por Leontiev (2006), as atividades realizadas pelas crianças em cada período de seu desenvolvimento. Segundo ele, em cada período do desenvolvimento psíquico a criança será marcada por uma determinada atividade, a qual proporcionará condições para sua humanização:

Chamamos de atividade principal aquela em conexão com a qual ocorrem as mais importantes mudanças no desenvolvimento psíquico da criança e dentro da qual se desenvolvem processos psíquicos que 
preparam o caminho da transição da criança para um novo e mais elevado nível de desenvolvimento. Leontiev (2006, p.122).

Elkonin discute a importância do jogo de papéis para o desenvolvimento infantil, partindo da premissa de que o mesmo fará parte da vida da criança quando a esta tiver superado a etapa anterior, denominada de atividade objetal manipulatória, ou seja, somente depois de constituídas as coordenações sensório-motoras necessárias para que ela consiga manusear objetos.

Quando isso ocorrer não será mais suficiente para ela pegar um determinado objeto com função especifica na mão, analisá-lo, e jogá-lo no chão, já que progressivamente percebeu a finalidade social do mesmo ao observar um adulto usandoo. Seu interesse agora incide em representar esse adulto em situações cotidianas fazendo uso do objeto em questão, pondo em prática um sentimento de pertencimento a esse universo adulto e às relações sociais pertinentes.

Nas palavras de Elkonin (2009, p.403) "o adulto e seus atos começam a ser um modelo para a criança", e esta "quer atuar como o adulto, sente-se totalmente dominada por esse desejo". Assim, entende-se que a transição qualitativa para um novo período de desenvolvimento do psiquismo humano pressupõe um acúmulo quantitativo de mudanças graduais.

É no ato de brincar que a criança se apropria de papéis sociais presentes em seu cotidiano, utilizando objetos disponíveis e realizando ações para representar procedimentos próprios dos adultos. Sendo assim, brincar de ser médico, professor, cozinheiro, bombeiro, etc. possibilita à criança reproduzir papéis sociais presentes no mundo adulto e consequentemente desenvolver certo pertencimento a esse universo. No entanto, como esse jogo pode ser a representação de cenas da vida real presenciada pela criança ou mesmo observada pela televisão, games ou em redes sociais, corre-se o risco desta mesma criança limitar-se a repetir atitudes próprias do cotidiano alienado. Observa-se que quanto mais restrito for o convívio social desta criança, mais limitados e pobres serão os enredos de seus jogos.

Sendo assim, torna-se necessária a interferência crítica do professor com direcionamentos adequados para que a criança possa reproduzir papéis sociais com enredos que desenvolvam ações humanizadoras, como descreve Lazaretti (2016, p.135):

A intervenção do professor pode ser a de incrementar com materiais, recursos, conhecimentos a respeito dessas atividades laborais, compartilhando com as crianças, brincando junto, instigando o enredo, levantando hipóteses de direcionamento das ações e operações. A 
brincadeira compartilhada permite a participação do professor não apenas como alguém que pode dirigir, mas de vivenciar com as crianças e perceber como elas vêm construindo seus conhecimentos a respeito do que envolve as funções de trabalho nas atividades produtivas dos adultos, incrementando e enriquecendo o conteúdo de valores e regras sociais que são fundamentais para se relacionar com o mundo circundante, em direção à almejada formação humana.

Desse modo, quanto mais a criança for provocada pelo professor a vivenciar situações diferenciadas, mais exitoso será o processo de apropriação e objetivação cultural, indispensável para o desenvolvimento da individualidade humana.

A intervenção intencional do professor demanda critério e planejamento. Jogos de papéis desafiadores, que estimulem a criatividade, espirito colaborativo, autoconfiança, respeito e solidariedade, entre tantos outros valores, são condições de potencialização dos processos de conscientização e humanização da criança, uma vez que contribuem para a apropriação da cultura material e simbólica construída pelo homem.

\section{Considerações finais}

Considerando a contribuição da psicologia histórico-cultural do desenvolvimento humano e das possibilidades de intervenção educativa a partir dos jogos de papéis, buscamos refletir sobre a importância da educação infantil com o fim, entre outros, de desmistificar a ideia de que essa modalidade de ensino teria por finalidade, além do assistencialismo, ocupar o tempo das crianças com possibilidades recreativas desinteressadas, ou seja, desvinculadas de conteúdos significativos para sua humanização.

Buscamos também refletir sobre o papel da educação infantil concebendo-a como espaço educativo e, portanto, formativo, a partir do comprometimento com um ideal de emancipação humana. Nesse sentido a obra de Elkonin contribuiu para essa assertiva ao apresentar as possibilidades de intervenção educativa por meio do jogo de papéis ou jogo protagonizado.

Procuramos, por fim, enfatizar o comprometimento do professor nos momentos de planejamento e seleção de conteúdos, priorizando aqueles cuja atividade dominante contribua para transformações significativas no psiquismo da criança de modo a contribuir, por sua vez, positivamente para a formação de sua personalidade. Em outras palavras, cabe ao professor comprometido com a perspectiva de construção de uma 
sociedade sem diferenças de classe, oferecer aos alunos enredos que possam contrastar a realidade alienada do cotidiano com possibilidades efetivamente humanizadoras, ou seja, que sinalizem para a apropriação dos conhecimentos socialmente produzidos e do desvelamento das formas de exploração e segregação existentes na sociedade.

O comprometimento do professor constitui elemento essencial para que a brincadeira de papeis sociais atinja resultados positivos. Conforme nossa perspectiva teórico-metodológico, anteriormente enunciada, tais resultados devem se expressar na aquisição ou desenvolvimento de sensibilidade social, na ruptura com os preconceitos, no reconhecimento da desigualdade social como produto histórico e não como decorrente do mérito individual de trabalhadores que foram bem-sucedidos graças a seus méritos e esforços pessoais. Para tanto, é condição sine qua non que o professor tenha ciência dos objetivos esperados, o que somente pode se dar se estiver conscientemente comprometido com a transformação social.

\section{Referências}

BRASIL, República Federativa do. Lei no 12.796, de 4 de abril de 2013. Altera a Lei no 9.394, de 20 de dezembro de 1996, que estabelece as diretrizes e bases da educação nacional, para dispor sobre a formação dos profissionais da educação e dar outras providências. Brasília, 2013.

CHEROGLU, S. Educação e desenvolvimento de zero a três anos de idade: contribuições da psicologia histórico-cultural para a organização do ensino. Dissertação (Mestrado em Educação Escolar) - Faculdade de Ciências e Letras da Universidade Estadual Paulista, Araraquara, 2014.

DUARTE, N. A brincadeira de papéis sociais como produtora de alienação no Referencial Curricular Nacional para a Educação Infantil. In: DUARTE, N. (Org.). Brincadeira de papéis sociais na educação infantil: as contribuições de Vigotsky, Leontiev e Elkonin. São Paulo: Xamã, 2006.

DUARTE, N. A Individualidade para si. Campinas: Autores Associados, 2013.

DUARTE, N. Formação do indivíduo, consciência e alienação: o ser humano na psicologia de A. N. LEONTIEV. Caderno Cedes, Campinas, v. 24, n. 62, p. 44-63, abril 2004. Disponível em: <http://www.cedes.unicamp.br>. Acesso em: 20 jul. 2016.

ELKONIN, D. Sobre el problema de la periodización del desarrollo psíquico em la infância. In: DAVIDOV, V. V.; SHUARE, M. (Org.) La psicologia evolutiva y pedagógica em la URSS: antologia. Moscou: Editorial Progresso, 1987.

ELKONIN, D. Psicologia do jogo. São Paulo: Martins Fontes, 2009. 
LAZARETTI, L. M. Idade pré-escolar (3-6anos) e a educação infantil: a brincadeira de papéis sociais e o ensino sistematizado. In: ARCE, A.; DUARTE, N. (Org). Brincadeira de papéis sociais na educação infantil: as contribuições de Vigotsky, Leontiev e Elkonin. São Paulo: Xamã, 2006.

LEONTIEV, A. Uma contribuição à Teoria do Desenvolvimento da Psique Infantil. In: Vigotski, L. S.; LURIA, A. R.; LEONTIEV, a. n. Linguagens, desenvolvimento e aprendizagem. São Paulo: Ícone, 2006.

LUKÁCS, G. Para uma ontologia do ser social. São Paulo: Boitempo, 2013.

MARTINS, L. M. O ensino e o desenvolvimento da criança de zero a três anos. In: ARCE, A.; MARTINS, L. M. (Orgs.). Ensinando aos pequenos de zero a três anos. Campinas, SP: Alínea. 2012.

MARTINS, L. M. A brincadeira de papéis sociais e a formação da personalidade. In: ARCE, A.; DUARTE, N. (Org). Brincadeira de papéis sociais na educação infantil: as contribuições de Vigotsky, Leontiev e Elkonin. São Paulo: Xamã, 2006.

PASQUALINI, J. C. A teoria histórico-cultural da periodização do desenvolvimento psíquico como expressão do método materialista dialético. In: MARTINS, L. M.; ABRANTES, A. A.; FACCI, M. G. D. (Org.). Periodização histórico-cultural do desenvolvimento psíquico. Campinas: Autores Associados, 2016.

PASQUALINI, J. C. Contribuições da psicologia histórico-cultural para a educação escolar de crianças de 0 a 6 anos: desenvolvimento infantil e ensino em Vigotski, Leontiev e Elkonin. Dissertação (Mestrado em Educação Escolar) - Faculdade de Ciências e Letras da Universidade Estadual Paulista, Araraquara, 2006.

SAVIANI, D. Pedagogia histórico-crítica: primeiras aproximações. $9^{\mathrm{a}}$ ed. Campinas, Autores Associados, 2005.

\section{Como referenciar este artigo}

CÁSSIA DUARTE, Rita de.; DERISSO, José Luis.; MELO DUARTE, Elaine Cristina.; DUARTE, Newton. Jogo de papéis ou jogo protagonizado na organização do ensino na educação infantil. Revista on line de Política e Gestão Educacional, Araraquara, v.21, n.2, p. 489-501, maio-ago. 2017. Disponível em: <http://dx.doi.org/10.22633/rpge.v21.n.2.2017.10186>. ISSN: 1519-9029.

Submetido em: 16/05/2017

Aprovado em: 16/07/2017 